\title{
Balanced and unbalanced, complete and partial transparency
}

\author{
FABIO METELLI, OSVALDO DA POS, and ADELE CAVEDON \\ University of Padua, Padua, Italy
}

\begin{abstract}
Beck, Prazdny, and Ivry's (1984) interpretation of Metelli's theory of phenomenal transparency is reexamined here. There are no constraints, because the theory considers only balanced transparency and nothing is asserted against the existence of forms of unbalanced transparency. Experiment 4 of the present study proves that conditions of intensity are primary for complete balanced transparency and cannot be overcome if figural conditions strongly suggest transparency. The equation $\alpha=(\mathrm{p}-\mathrm{q}) /(\mathrm{a}-\mathrm{b})$ does not require further restrictions because the cases cited by Beck et al. concern nonbalanced transparency. Experiment 1 proves that figural conditions cannot be considered primary and thus be the cause of the perception of transparency. The present paper reports that, contrary to the results Beck et al. obtained in their Experiment 4, a series of experiments in which experienced subjects were used and in which estimation of transparency was compared with predictions calculated with the $\alpha$ formula gave satisfactory results. Beck et al.'s thesis, according to which $\alpha \neq \alpha^{\prime}$ hinders transparency whereas $t \neq t^{\prime}$ allows it, is confirmed. Ex perienced subjects and simple instructions appear to yield clearer results.
\end{abstract}

Beck, Pradzny, and Ivry's (1984) paper, "The perception of transparency with achromatic colors," starts with an exposition of the theory of transparency proposed by the senior author of this paper, which however lacks an essential part.

The theory, based on Heider's (1933) theory and, restated by Koffka (1935), is that transparency is a phenomenal scission, in which a stimulation-which, if isolated, gives rise to a single color-gives rise, with scission, to the perception of two colors: the color of the object seen through transparency and the color of the transparent layer. Heider's and Koffka's experiments also demonstrated that scission colors are such that if fused, when transparency is not perceived, they give rise to the color seen in isolation (that is, to the reduction color).

Heider's and Koffka's results allow a quantitative interpretation. Talbot's law, which permits a quantitative description of chromatic fusion, also provides one for chromatic scission as well. In other words, if Talbot's law for the fusion of the two colors ${ }^{1}$ is expressed by $\alpha \mathrm{a}+(1-\alpha) \mathrm{b}=\mathrm{c}$ [where $\mathrm{a}$ and $\mathrm{b}$ are the reflectances of the two colors that are fused, $c$ is the reflectance of the fusion color, $\alpha$ and $(1-\alpha)$ are the proportions in which the two colors are mixed], then the same formula reads, so to speak, backwards. That is, $\mathrm{c}=\alpha \mathrm{a}+(1-\alpha) \mathrm{b}$ will describe the scission of color $c$ into the two colors a, seen through transparency, and $b$, perceived as transparent; $\alpha$ and $(1-\alpha)$ are the proportions into which color $\mathrm{c}$ splits when giving rise to colors $a$ and $b$.

The typical situation to which the theory refers is the transparency obtained using an episcotister. If an episcotister (that is, a disk lacking a sector) rotates at fusion

The author's mailing address is: Istituto di Psicologia, Piazza Capitaniato 3,35139 Padua, Italy. speed before a bicolored ground, the perceptual result is a gray transparent disk, through which the colors of the background are visible (Figure 1). Figure 1a indicates the symbols of the four resulting regions; that is, A and B are parts of the bicolored ground that are directly visible, and $\mathrm{P}$ and $\mathrm{Q}$ are regions where a transparent disk, $T$, and parts of the underlying background are perceived. But if part of one of the regions where scission is perceived is isolated with a pierced screen, scission disappears and a single fusion color, $\mathrm{p}$, in the $\mathrm{P}$ region, or $\mathrm{q}$, in the $\mathrm{Q}$ region, is perceived through the hole. ${ }^{2}$

The situation can be described by the following two equations.

$$
\begin{gathered}
p=\alpha \mathrm{a}+(1-\alpha) \mathrm{t} \\
\mathrm{q}=\alpha \mathrm{b}+(1-\alpha) \mathrm{t}
\end{gathered}
$$

where $a, b, p$, and $q$ are the reflectances of the respective regions (Figure 1a), $t$ is the virtual reflectance of the transparent layer $\mathrm{T}$, and $\alpha$ and $(1-\alpha)$ are the proportions into which the $p$ and $q$ colors split in giving rise to the color of that part of region A (or B) seen through transparency, and to the transparent layer $T .^{3}$

From the system of two equations with two unknowns, the values of $\alpha$ and $t$ can be obtained; that is,

$$
\begin{gathered}
\alpha=(p-q) /(a-b) \\
t=(a q-b p) /[(a+q)-(b+p)] .
\end{gathered}
$$

However, one must keep in mind-a thing Beck et al. failed to do-that the deduction of Equations 3 and 4 is valid only in the case of the episcotister, where the $\alpha \mathrm{s}$ and the ts are the same in Equations 1 and $2 .^{4}$ 

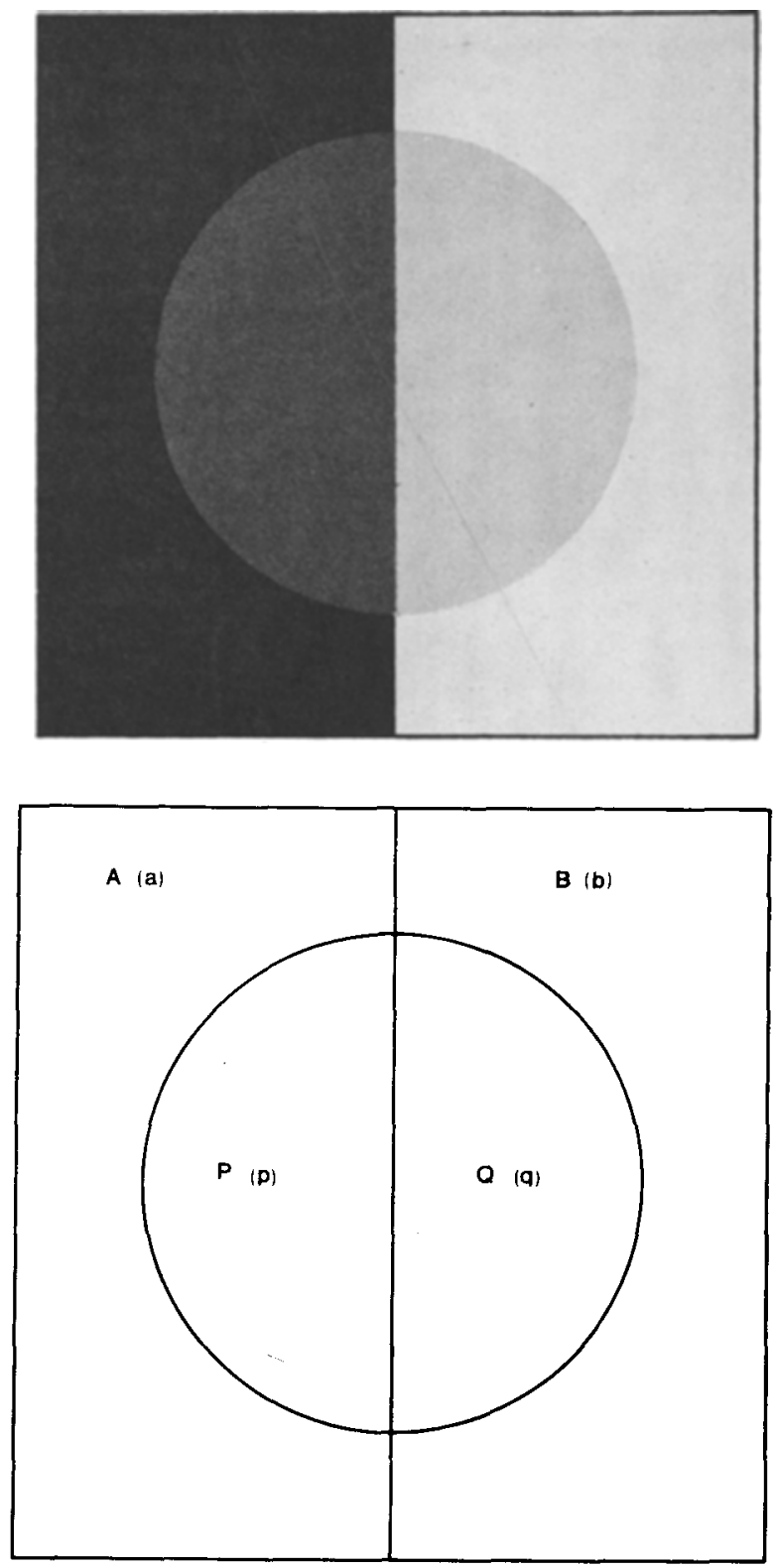

Figure 1. An example of chromatic scission similar to that obtained with the episcotister (transparent disk on bicolor ground). (a) APBQ (capital letters) indicate the regions, and a p q b (small letters) indicate the relative reflectances.

If a figure like Figure 1 is constructed by selecting the two grays, $p$ and $q$, arbitrarily, Equations 1 and 2 become

$$
\begin{gathered}
\mathrm{p}=\alpha \mathrm{a}+(1-\mathrm{a}) \mathrm{t} \\
\mathrm{q}=\alpha^{\prime} \mathbf{b}+\left(1-\alpha^{\prime}\right) \mathbf{t}^{\prime},
\end{gathered}
$$

and then, as there are four unknowns $\left(\alpha, \alpha^{\prime}, t, t^{\prime}\right)$, the system becomes indeterminate and Equations 3 and 4 can no longer be deduced from Equations 1 and 2-in other words, only when $\alpha=\alpha^{\prime}$ and $\mathrm{t}=\mathrm{t}^{\prime}$ is the above-mentioned deduction lawful. This case has been called balanced transparency, where the degree $\alpha$ and the color $t$ of the transparent layer are equal in the $P$ and $Q$ regions.

Beck et al. interpret limitations relative to $\alpha(\mathrm{O}<\alpha<1)$ and $t(0<t<1)$ as true constraints-namely, as insuperable limits-thus putting the validity of the theory to the test. In fact, the conditions studied apply only to balanced transparency. If transparency occurs outside the aforesaid limits, then the transparency is unbalanced, and the theory makes no assertions about the possible existence of forms of nonbalanced transparency.

It is interesting to consider more closely what happens if these limits are surpassed. It has been noted in preceding papers that $\alpha>1$ and $\alpha<0$ give rise to results devoid of sense; the same is true for $t>1$ and $t<1 .^{5}$ Results of this type are absurd. It is then natural to ask if the premises that give rise to these results are not satisfied.

In obtaining results from the two initial equations, psychological equality was supposed between $\alpha$ and $\alpha^{\prime}$ and between $t$ and $t^{\prime}$. The most reasonable hypothesis, when results are absurd, is that the premise must be wrong. That is, every time the system of two equations with two unknowns yields an absurd result, the premise-that is, $\alpha=\alpha^{\prime}$ and $/$ or $\mathrm{t}=\mathfrak{t}^{\prime}$-must be erroneous.

On the basis of this hypothesis, $\alpha<0$ or $\alpha>1$, or $\mathrm{t}<0$ or $\mathrm{t}>1$, means only that $\alpha \neq \alpha^{\prime}$ and/or $\mathrm{t} \neq \mathrm{t}^{\prime}$-in other words, that it is incorrect to solve the system of two unknowns and therefore the results are devoid of meaning.

The hypothesis suggests a concrete expectation. If there is transparency when $\alpha>1$ or $\alpha<0, \alpha \neq \alpha^{\prime}$, and transparency is unbalanced, since there is a different degree of transparency in the two regions. If there is transparency when $\mathrm{t}>1$ or $\mathrm{t}<0, \mathrm{t} \neq \mathrm{t}^{\prime}$; that is, in the two regions, there is a different color, or, in other words, $T$ will be lighter than $T^{\prime}$, or vice versa.

It may perhaps be useful to go back to the example of the episcotister, where $\alpha$ corresponds to the empty sector of the episcotister and $t$ corresponds to the episcotister's reflectance. $\alpha<0$ and $\alpha>1$ means that the opening of the episcotister should be less than $0^{\circ}$ or greater than $360^{\circ}$, which is absurd. Equally absurd, for the aforesaid reasons, is $t<0$ or $t>1$. Because, with the episcotister, the unknowns are $p$ and $q$, there are certain values of $p$ and $q$ that, when $a$ and $b$ have given values, cannot be obtained with an episcotister. These values of $p$ and $q$ could be obtained by setting, if it were possible, two episcotisters, one in place of $\mathrm{T}$ and the other in place of $T^{\prime}$ (Figure 2), with different values for $\alpha$ and $t$ in each episcotister. Therefore, what cannot be obtained with $\alpha$ and $\mathrm{t}$ can be obtained with $\alpha, \alpha^{\prime}, \mathrm{t}$, and $\mathrm{t}^{\prime}$, that is, by carrying out, if it were possible, a form of nonbalanced transparency using two episcotisters.

Summarizing, our theory does not give rise to constraints, because it indicates the limits only of balanced transparency, and does not deny the possibility of forms of nonbalanced transparency beyond these limits. 


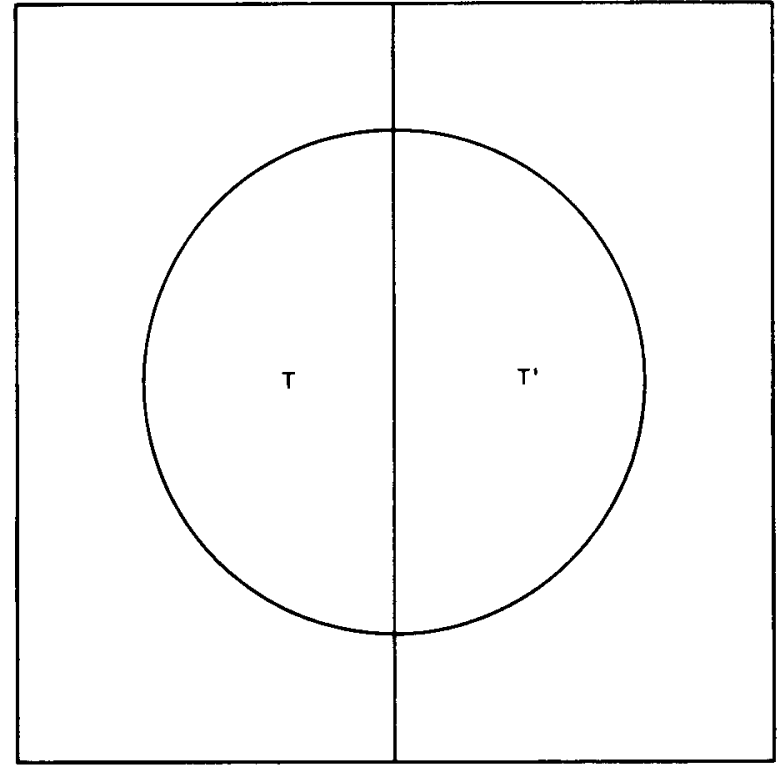

Figure 2. Where the two episcotisters would be located if it were possible (see text).

Furthermore, the preceding hypothesis, which interprets results beyond the limits as cases of unbalanced transparency, suggests the possibility that results of $\alpha$ beyond the limits indicate a form of transparency that is unbalanced in degree, whereas results of $t$ beyond the limits indicate a form of transparency that is unbalanced in color. The concept of balanced transparency is defined in terms of physical measures in our theory. It is, however, possible to treat mathematically the aspects of balanced transparency starting from perceptual measures, that is, from lightness estimates.

The first person to consider the possibility of predicting perceptual transparency starting from perceptual estimations instead of reflectances was Beck. The next step should have been the deduction of a new theory. Beck simply used the equation $\mathrm{p}=\alpha \mathrm{a}+(1-\alpha) \mathrm{b}$ (which had been deduced for physical measures) with perceptual measures, that is, estimations of lightness (giving, however, theoretical justifications). The result was an excellent prediction of estimated transparency.

The reason for this success was explained when the senior author of this paper deduced the equations for predicting estimated transparency, starting with the estimated lightness of the surfaces involved in the phenomenon: the equations were formally identical to the equations that had been deduced for physical measures. So Beck's happy intuition was confirmed by the theory.

However, the theory not only predicts the perceptual measures of partial transparency (the case of Beck's prediction), but also the perceptual measure of complete balanced transparency. And here our results seem to be quite different from Beck et al.'s (see Beck et al., 1984, pp. 420-421, and point 8 of Discussion in the present paper).
Our conclusion is that, notwithstanding the formal equality of the equations, there are two different theories, one valid when we are working with reflectances and the other valid when we are working with estimations of lightness.

Some of the statements and conclusions in Beck et al.'s (1984) paper suggest or require a series of experiments. In doing these experiments, we decided to differ from Beck et al. on the following points:

(1) Although Beck et al. followed tradition by using naive subjects, we were conscious of the considerable difficulty involved in giving a phenomenological description in this type of experiment. Therefore, we used a more limited number of expert subjects, ones who were used to this type of experiment, accustomed to the difficulty of giving an objective description of what they saw, and used to distinguishing between complete and partial transparency, tasks that are easily confused by naive subjects. ${ }^{6}$

(2) Instead of limiting the task of the subject to describing one form of transparency, we invited the subjects to describe every form of transparency and questioned them every time the description did not appear to be sufficiently clear. In addition to the difference between complete and partial transparency and the various possible forms of inversion, we used different forms of complete transparency (see Experiment 2) that appeared with the same type of display, along with variations in the order of the lightness of the grays.

(3) Subjects were free to observe the figure for as long as they needed, and had it in front of them when they gave their descriptions. Since inversions are quite common during observation, the subjects were also requested to describe the new form of any change that might occur in the transparency, observed successively.

\section{EXPERIMENT 1}

The purpose of this experiment was to test Beck et al.'s (1984, pp. 412, 421) thesis that figural conditions are primary and are the necessary clue for perceiving transparency.

\section{Method}

Subjects. Eight experienced subjects took part in the experiment. They required no explanations of preliminary experiments, since they were already used to the task involved. They were only told to describe transparencies, if there were any.

Displays. The configuration was the simplest possible and by no means suggested transparency (Figure 3). Four gray rectangular regions, $3 \times 5 \mathrm{~cm}$ wide and with different reflectances, were juxtaposed (Figure 3a). The grays were, respectively, Nos. 9.5, 7, 4.5 , and 2 of the Munsell series, corresponding to $.03, .16, .43$, and .90 reflectance, respectively. There were only 12 displays, corresponding to 12 permutations, because, since the figure was symmetrical, the other 12 were useless, in that they corresponded to the same figures with the rectangles in the inverse order.

The figures were attached to pieces of brown cardboard, which formed a $2-\mathrm{cm}$-wide frame. Each display was symbolized by four lowercase letters indicating the order of reflectance from the lowest to highest, as Beck et al. had done. The order of the grays in the displays was APQB. 

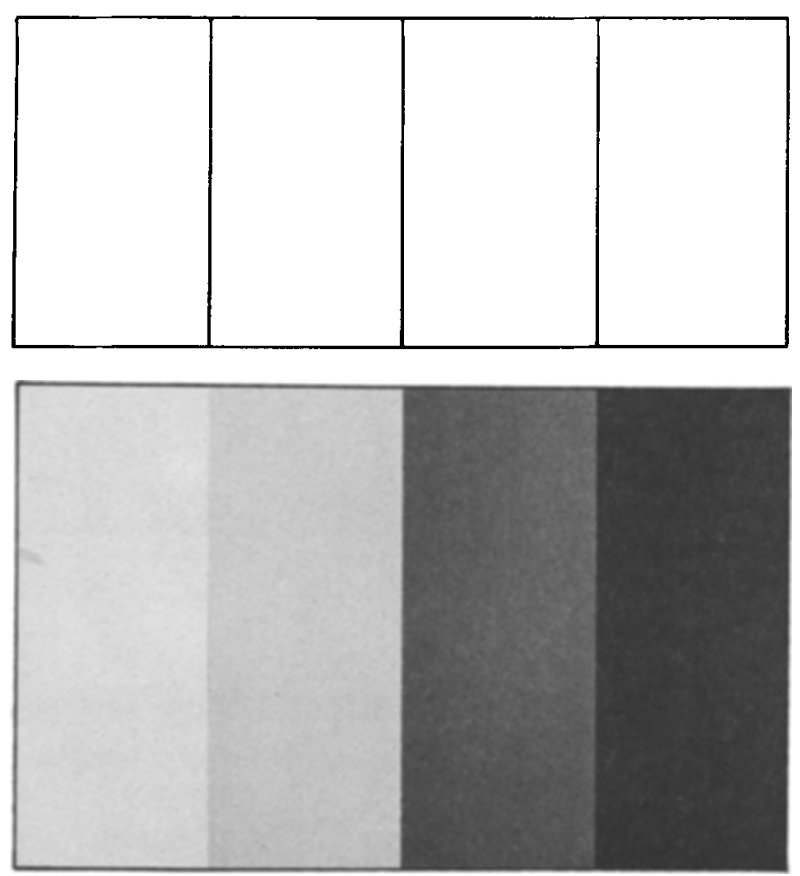

Figure 3. Linear drawing of a display in Experiment 1. (a) Example of a display in Experiment 1.

Procedure. The figures were presented in succession to each subject at a distance of about $50 \mathrm{~cm}$. There was no time limit. The subjects observed the figures for as long as they felt they had something to describe. Their task was to describe the form or forms of transparency, if any, and also to indicate any changes during observation. The subjects' descriptions were recorded and subsequently summarized in a table.

\section{Results}

Table 1 gives the results, including the number of cases of complete transparency (transparency on two regions of the background), partial transparency (transparency on one region of the background only), and cases of nontransparency. The numbers in parentheses indicate cases in which a subject gave a second description.

It is interesting to note that in Experiment 1 every subject perceived at least one case of complete transparency. Cases of partial transparency were very frequent. One display gave rise only to impressions of nontransparency. The subject's answers can be reconstructed from the table.

The results show clearly that, in a figurally neutral situation (that is, in a configuration which, when drawn linearly, has nothing to suggest transparency), complete or partial transparency is perceived rather frequently. Therefore, figural conditions cannot be considered primary, and be the cause of the perception of transparency. $^{7}$

\section{EXPERIMENT 2}

\section{Method}

Subjects. Ten experienced subjects (including the eight from Experiment 1) took part in this experiment. They did not require any explanations or preliminary experiments.

Displays. Although the purpose was the same as in Experiment 1, the displays were more complicated than those of Experiment 1 . Here too, drawn linearly (Figure 4), the configuration does not suggest transparency in any way. Eight gray regions were juxtaposed, as on a checkerboard; there were two lines of four $3 \times 3 \mathrm{~cm}$ squares, with the second line being the inverse of the first. The order of grays in the first line was the same as that in the displays of Experiment 1 . In this case also, 12 displays were used, since the figures

Table 1

Results of Experiment 1

\begin{tabular}{|c|c|c|c|c|c|c|}
\hline \multirow{2}{*}{$\begin{array}{c}\text { Displays } \\
\text { (Order of } \\
\text { Reflectances) }\end{array}$} & \multicolumn{2}{|c|}{ Transparency } & \multirow{2}{*}{$\begin{array}{c}\text { Non- } \\
\text { transparent }\end{array}$} & \multirow{2}{*}{$\begin{array}{c}\text { Double } \\
\text { Response } \\
\text { Description }\end{array}$} & \multirow[b]{2}{*}{$\alpha$} & \multirow[b]{2}{*}{$t$} \\
\hline & Complete & Partial & & & & \\
\hline 1 bqpa & 8 & $(+2)$ & - & $2<\frac{\mathrm{CT}}{\mathrm{PT}}$ & .31 & .4 \\
\hline 2 baqp & 1 & $7(+1)$ & - & $1<{ }_{\mathrm{PT}}^{\mathrm{CT}}$ & 1.08 & -2.53 \\
\hline 3 bqap & 1 & 7 & - & - & 1.04 & -2.53 \\
\hline 4 qbpa & - & 8 & - & - & 1.04 & -2.53 \\
\hline 5 qpba & - & 2 & 6 & - & .96 & -2.53 \\
\hline 6 bpaq & 1 & 3 & 4 & - & -1.08 & .4 \\
\hline 7 bpqa & - & 1 & 7 & - & -.31 & .41 \\
\hline 8 pbqa & - & 2 & 6 & - & -.96 & .41 \\
\hline 9 pabq & 1 & 3 & 4 & - & -3.27 & .4 \\
\hline 10 qabp & - & - & 8 & - & -3.27 & .4 \\
\hline 11 bapq & 1 & $7(+1)$ & - & $1<{ }_{\mathrm{PT}}^{\mathrm{CT}}$ & -1.08 & .4 \\
\hline 12 pqab & 1 & 7 & - & - & -.92 & .4 \\
\hline
\end{tabular}

that transparency is perceived even when there are no figural conditions favorable to transparency. 
were symmetrical. As before, the order of symbols corresponds to the order of reflectances, from the lowest to the highest. The order of grays was APQB (first line) and $B^{\prime} Q^{\prime} P^{\prime} A^{\prime}$ (second line). The colors were the same as in Experiment 1.

Procedure. The procedure was the same as in Experiment 1.

\section{Results}

The results are given in Table 2 . In this case, the entries are more complicated, because complete transparency appears in three different locations. That is, in (a) the four central squares appear transparent (Figure 4a), in (b) the four lateral squares appear transparent (Figure 4b), and in (c) the couples AP (left) and $\mathrm{A}^{\prime} \mathrm{P}^{\prime}$ (right) appear transparent (Figure 4c).

It should, however, be noticed that, when transparency appears in different forms, the functions of the gray squares change. Although in Form a of transparency, in which the central four squares are transparent, $P$ and $Q$ in both lines of squares indicate the regions in which perceptual scission takes place and transparency is perceived, this is not true for the other forms of transparency. In the case of Form b, in which the outer squares are transparent, $A B^{\prime}$ and $B^{\prime}$ assume the functions of $P$ and $Q$. In the case of Form $c$, in which the couples $A P$ and $A^{\prime} P^{\prime}$ are perceived as transparent, $A$ and $P$, and $A^{\prime}$ and $P^{\prime}$, assume the functions of $\mathrm{P}$ and $\mathrm{Q}$.

Table 2

Results of Experiment 2

\begin{tabular}{|c|c|c|c|c|c|c|}
\hline \multirow{2}{*}{\multicolumn{2}{|c|}{$\begin{array}{c}\text { Displays } \\
\text { Order of } \\
\text { Reflectance } \\
\end{array}$}} & \multicolumn{3}{|c|}{$\begin{array}{c}\text { Complete } \\
\text { Transparency } \\
\end{array}$} & \multirow{3}{*}{$\begin{array}{c}\begin{array}{c}\text { Partial } \\
\text { Transparency }\end{array} \\
-\end{array}$} & \multirow{3}{*}{$\frac{\text { Nontransparent }}{-}$} \\
\hline & & \multirow{2}{*}{$\frac{a}{10}$} & \multirow{2}{*}{$\begin{array}{l}\mathrm{b} \\
-\end{array}$} & \multirow{2}{*}{-} & & \\
\hline 1 & $\begin{array}{l}\text { bqpa } \\
\text { apqb }\end{array}$ & & & & & \\
\hline 2 & $\begin{array}{l}\text { baqp } \\
\text { abpq }\end{array}$ & 3 & 1 & - & 6 & - \\
\hline 3 & $\begin{array}{l}\text { bqap } \\
\text { apbq }\end{array}$ & 3 & 1 & 1 & 5 & - \\
\hline 4 & $\begin{array}{l}\text { qbpa } \\
\text { paqb }\end{array}$ & 8 & - & - & 2 & - \\
\hline 5 & $\begin{array}{l}\text { qpba } \\
\text { pqab }\end{array}$ & 5 & - & - & 5 & - \\
\hline 6 & $\begin{array}{l}\text { bpaq } \\
\text { aqbp }\end{array}$ & - & - & - & - & 10 \\
\hline 7 & $\begin{array}{l}\text { bpqa } \\
\text { qapb }\end{array}$ & 5 & - & - & - & 5 \\
\hline 8 & $\begin{array}{l}\text { pbqa } \\
\text { qapb }\end{array}$ & - & - & - & - & 10 \\
\hline 9 & $\begin{array}{l}\text { pabq } \\
\text { qbap }\end{array}$ & - & 10 & - & - & - \\
\hline 10 & $\begin{array}{l}\text { qabp } \\
\text { pbaq }\end{array}$ & - & 3 & - & 1 & 6 \\
\hline 11 & $\begin{array}{l}\text { bapq } \\
\text { abqp }\end{array}$ & - & - & 10 & - & - \\
\hline 12 & $\begin{array}{l}\text { pqab } \\
\text { pqba }\end{array}$ & - & - & 10 & - & - \\
\hline
\end{tabular}

Note-The purpose of the experiment was the same as in Experiment 1. In this case, although there are no figural conditions favorable to transparency, there are very evident and constant impressions of transparency.
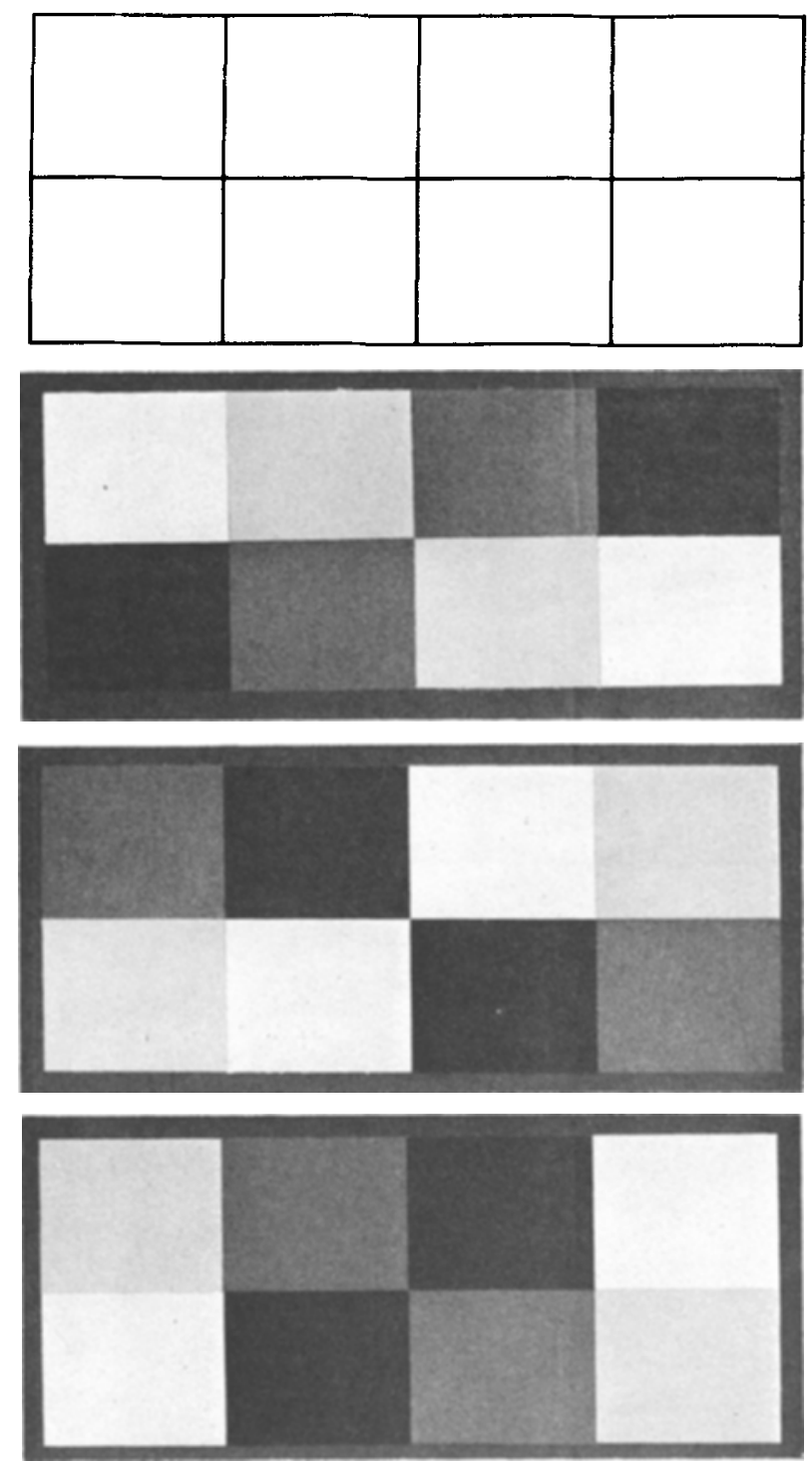

Figure 4. Linear drawing of a display in Experiment 2. (a, b, c) Three typical displays in Experiment 2.

Averages therefore have not been calculated, as there is no relation between these results and those obtained by Beck et al.

General results are again very clear: there are four figures in which all subjects perceived complete transparency and two figures in which no subject perceived transparency. Cases of partial transparency are spread among the other displays.

In this experiment, in which displays are figurally neutral, the cases of transparency outnumber those found in experiments in which figural factors were at work.

\section{EXPERIMENT 3}

Experiment 3 was a repetition of Beck et al.'s (1984) Experiment 1, with slight variations in the reflectances 
used [Natural Colour System (Swedish) papers' reflectances were $.23, .35, .46$, and .59 versus $.22, .34, .47$, .59 of Beck et al.'s Experiment 1]. The aim of this experiment was to test the results using experienced as opposed to inexperienced subjects.

\section{Method}

Subjects. The 10 subjects were those who took part in Experiment 2 .

Displays. The displays were figurally the same as those used by Beck et al. An example of the displays can be seen in Figure 5, in which the letters symbolizing the different regions also appear. Twenty-four displays, corresponding to the 24 permutations of four colors, were used.

Procedure. The procedure was the same as that described for Experiment 1.

\section{Results}

In Table 3, our results are given in detail as before and are compared with those of Beck et al. (1984, Experiment 1). Line 1 of the table reads as follows: (1) order of reflectance, $a<b<p<q$; (2) complete transparency, 6 cases; (3) inverted complete transparency, 2 cases ( 5 cases of double response); (4) partial transparency, 2 cases ( 1 case of double response); (5) nontransparency, 0 cases; (6) description of cases of double response, 5 cases of complete and of inverted complete transparency, and 1 case of complete and of partial transparency; (7) Beck et al.'s results, 15 cases of complete transparency; (8) $\alpha$ $=1.08 ;(9) \mathrm{t}=-2.53$.

Taking into account the different tasks given to subjects, there is a fairly good agreement between our results and Beck et al.'s for the first 10 displays. The few cases of nontransparency in Beck et al.'s results can be explained by the cases of inversion and partial transparency

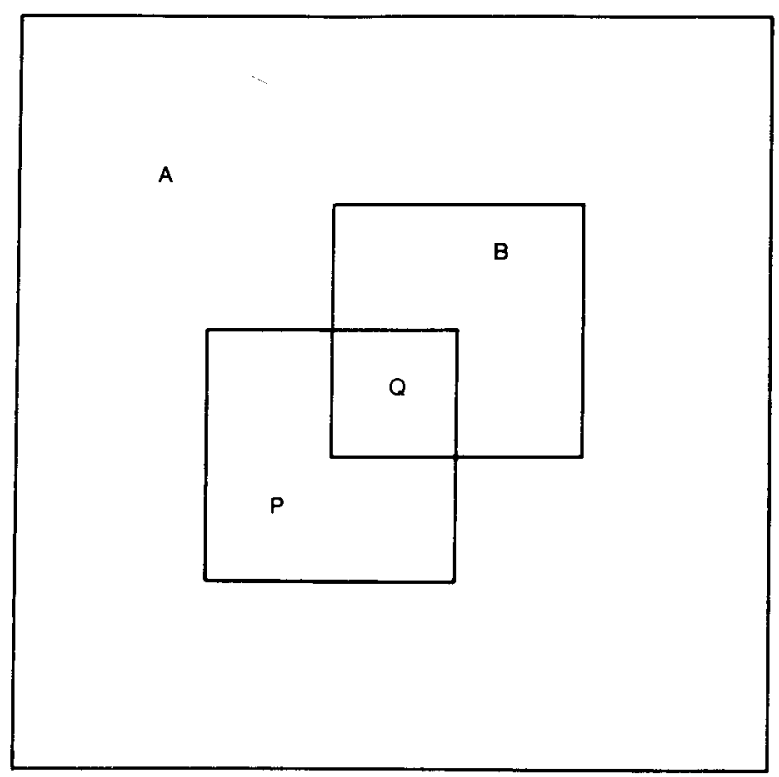

Figure 5. Linear drawing of a display in Experiment 3 (see Beck et al., 1984, Figure 2a) with letters indicating regions. in our subjects' responses, which included no case of nontransparency.

As shown in the second part of the table, Beck et al.'s subjects described almost exclusively cases of nontransparency. There are, however, very patent cases, as in those of Displays 21, 22, and 23, in which several of Beck et al.'s subjects described complete transparency, but our subjects described only inversions or partial transparencies. In other words, exceptions are not found when experienced subjects are used, especially when the subjects are asked to describe every form of transparency.

\section{EXPERIMENT 4}

The purpose of this experiment was to test the effect of a situation in which some nonchromatic factors (such as form and motion) strongly favored the impression of transparency. The new factor characterizing our experiments concerned the (apparent) motion of the transparent layer with respect to the figure seen through transparency, or vice versa. This configuration is similar to that in which Metzger (1955), when using different colors instead of different shades of gray, obtained anomalous transparency.

\section{Method}

Subjects. The same 10 subjects of Experiments 2 and 3 took part in this experiment.

Displays. Disks rotating slowly ( 2 rotations $/ \mathrm{sec}$ ) were used as displays. The configurations consisted of a circle, whose center corresponded to the rotation center, that was intersected by a smaller circle lying partly on the top of the first and partly on a circular ring (Figure 6). When the disk was rotated, the centered circle and the ring were perceived at rest, while the small, noncentered circle was perceived as moving either on the top of or below the circular ring.

The displays were constructed from the same papers used for Experiment 3. Twenty-four disks were used, corresponding to the order of colors in Beck et al.'s displays, so as to make the comparison easier." The diameter of the disks was $20 \mathrm{~cm}$, the diameter of the centered circle, $10 \mathrm{~cm}$, and the diameter of the eccentric circle, $6 \mathrm{~cm}$.

Procedure. The procedure was the same as before.

\section{Results}

The most interesting result is that in six displays subjects were unanimous in not perceiving transparency (see Table 4). This proves that not even the most coercive nonchromatic conditions succeed in creating the impression of transparency when intensity conditions are against it. For two other displays, cases of nontransparency were, respectively, 9 and 6 . In the other displays, the cases of total and partial transparency were very frequent, as expected, given the presence of very powerful factors favoring transparency. Cases in which the eccentric circle was perceived as below instead of on top of the centered circle were classified as inverted transparency.

An important point is the remarkable correspondence of results in very different conditions. The cases of nontransparency correspond exactly with those in which Beck 
Table 3

Results of Experiment 3

\begin{tabular}{|c|c|c|c|c|c|c|c|c|}
\hline \multirow{2}{*}{$\begin{array}{c}\text { Displays } \\
\text { Order of } \\
\text { Reflectances } \\
\text { (1) }\end{array}$} & \multicolumn{3}{|c|}{ Transparency } & \multirow[b]{2}{*}{$\begin{array}{c}\text { Non- } \\
\text { transparent } \\
\text { (5) }\end{array}$} & \multirow{2}{*}{$\begin{array}{l}\text { Double } \\
\text { Response } \\
\text { Description } \\
(6)\end{array}$} & \multirow{2}{*}{$\begin{array}{c}\text { Complete } \\
\text { Transparency } \\
\text { (Beck et al., 1984) } \\
\text { (7) }\end{array}$} & \multirow[b]{2}{*}{$\begin{array}{c}\alpha \\
(8)\end{array}$} & \multirow[b]{2}{*}{$\begin{array}{l}\mathrm{t} \\
(9)\end{array}$} \\
\hline & $\begin{array}{c}\text { Complete } \\
\text { (2) }\end{array}$ & $\begin{array}{c}\text { Complete } \\
\text { Inverted } \\
(3)\end{array}$ & $\begin{array}{l}\text { Partial } \\
\text { (4) }\end{array}$ & & & & & \\
\hline 1 abpq & 6 & $2(+5)$ & $2(+1)$ & - & $5<{ }_{\mathrm{CIT}}^{\mathrm{CT}} 1<{ }_{\mathrm{PT}}^{\mathrm{CIT}}$ & 15 & 1.08 & -2.53 \\
\hline 2 apbq & 5 & $3(+4)$ & $2(+1)$ & - & $4<{ }_{\text {CIT }}^{\text {CT }} 1<<_{\text {PT }}^{\text {CIT }}$ & 18 & 1.05 & -2.53 \\
\hline 3 apqb & 10 & - & $(+1)$ & - & $1<\frac{\mathrm{CT}}{\mathrm{PT}}$ & 18 & .31 & .4 \\
\hline 4 baqp & 3 & $4(+1)$ & $3(+3)$ & - & $1<{ }_{\mathrm{CIT}}^{\mathrm{CT}} 3<{ }_{\mathrm{PT}}^{\mathrm{CIT}}$ & 18 & -1.08 & .4 \\
\hline 5 bqap & 7 & $1(+2)$ & $2(+1)$ & - & 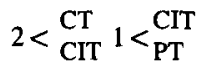 & 21 & 1.04 & -2.53 \\
\hline 6 bqpa & 10 & $(+1)$ & $(+1)$ & - & 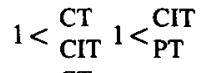 & 21 & .31 & .4 \\
\hline 7 qbpa & 7 & $2(+5)$ & 1 & - & $5<\frac{\mathrm{CT}}{\mathrm{CIT}}$ & 21 & .06 & -2.53 \\
\hline $8 \mathrm{qpba}$ & 8 & $1(+4)$ & $1(+2)$ & - & $4<{ }_{\mathrm{CIT}}^{\mathrm{CT}} 2<{ }_{\mathrm{PT}}^{\mathrm{CIT}}$ & 18 & .92 & -2.53 \\
\hline 9 paqb & 4 & $3(+2)$ & $3(+1)$ & - & $2<{ }_{\text {CIT }}^{\text {CT }} 1<<_{\text {PT }}^{\text {CIT }}$ & 18 & .96 & -2.53 \\
\hline $10 \mathrm{pqab}$ & 6 & $1(+4)$ & $3(+1)$ & - & $4<\underset{\mathrm{CIT}}{\mathrm{CT}} 1<{ }_{\mathrm{PT}}^{\mathrm{CT}}$ & 17 & .92 & -2.53 \\
\hline 11 aqbp & - & 1 & - & 9 & - & 1 & -1.04 & .41 \\
\hline $12 \mathrm{aqpb}$ & - & - & - & 10 & - & 2 & -.31 & .41 \\
\hline 13 bpqa & - & - & 1 & 9 & - & - & -1.04 & .41 \\
\hline 14 bpqa & - & - & - & 10 & - & - & -.31 & .41 \\
\hline 15 qapb & - & - & - & 10 & - & - & -.96 & .41 \\
\hline $16 \mathrm{pbqa}$ & - & - & - & 10 & - & 1 & -.96 & .41 \\
\hline 17 qbap & - & 1 & 3 & 6 & - & - & 3.27 & .4 \\
\hline 18 pabq & - & - & 4 & 6 & - & 1 & 3.27 & 4 \\
\hline 19 qabp & - & - & - & 10 & - & - & -3.27 & .41 \\
\hline 20 pbaq & - & - & - & 10 & - & - & -3.27 & .41 \\
\hline 21 abqp & - & 9 & $1(+2)$ & - & $2<\underset{\mathrm{CT}}{\mathrm{CIT}}$ & 3 & -1.08 & .4 \\
\hline 22 bapq & - & - & 4 & 6 & - & 6 & -1.83 & .4 \\
\hline 23 qpab & - & - & 5 & 5 & - & 13 & -.92 & .4 \\
\hline $24 \mathrm{pqba}$ & - & 9 & 1 & - & - & 2 & -.92 & .4 \\
\hline
\end{tabular}

et al. found a majority of cases of nontransparency. On the other hand, another important point is the absence of cases of complete transparency with Display 23, where all our subjects perceived partial transparency, whereas Beck et al. reported the inexplicable result of 13 cases of complete transparency. It is probable that in all 13 of these cases of partial transparency the inexperienced subjects were forced by an unnatural task ${ }^{8}$ to make an interpretion of complete transparency.

It has to be stressed that, on the whole, there were fewer descriptions of complete transparency in our experiments, whereas partial transparencies were frequent. 


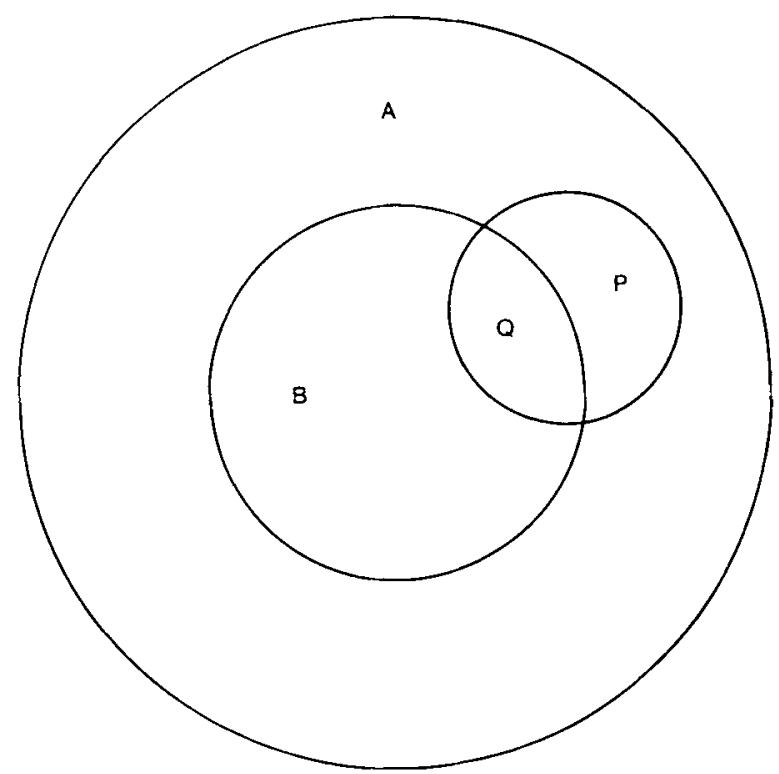

Figure 6. Linear drawing of a display in Experiment 4 with letters indicating regions.

\section{EXPERIMENT 5}

The purpose of this experiment was to test the assertion made by Beck et al. (1984) that conditions $t<0$ and $t>1$ do not hinder transparency, contrary to what happens when $\alpha<0$ and $\alpha>1$.

\section{Method}

Subjects. The same 10 experienced subjects were used.

Displays. Forty displays were constructed: 10 where $\alpha<0$ while $t$ was between 0 and 1,10 where $\alpha>1$ while $t$ was between 0 and 1,10 where $t<0$ while $\alpha$ was between 0 and 1 , and 10 where $t>1$ while $\alpha$ was between 0 and 1 . The displays corresponded to Beck et al.'s (1984) Figure $2 a$ and our Figure 5.

Procedure. The procedure was the same as that described for Experiment 1.

\section{Results}

The results are given in Tables 5 to 8 . From Table 5 it appears that there were no cases of complete transparency $(\alpha<0)$. The great majority of subjects responded "nontransparent." There are some cases of inversion and of partial transparency.

Table $6(\alpha>1)$ is characterized by a great number of inversions. As already pointed out, in cases of inversions $\alpha$ changes and therefore these are not cases in which $\alpha>1$. There are also some cases of partial transparency. Only two cases out of 100 (10 displays $\times 10$ subjects) are described as complete transparencies. These are likely to be cases of inexact descriptions. So it seems that transparency is excluded when $\alpha \neq \alpha^{\prime}(\alpha<0, \alpha>1)$.

In Tables 7 and $8(t<0, t>1)$, the results are completely different. Cases of nontransparency are the exception rather than the rule, and all displays give rise to some cases of transparency. In Table 7, there are three cases of nontransparency, with the same display, which other- wise is judged as transparent by four subjects. Nothing different appears in Table 8, which lists six cases of nontransparency, all with displays other subjects judged as transparent. The results thus confirm Beck et al.'s thesis.

We may conclude that unbalanced transparency with $t \neq t^{\prime}$ does occur. Given the low number of cases in which complete transparency is perceived, however, it seems probable that unbalanced transparency with regard to color is an unfavorable condition for the perception of transparency.

\section{DISCUSSION}

In their paper, Beck et al. (1984) set forth a series of theses, some of which will be discussed in this section. Apart from theses regarding the theory, which we discussed in the introduction, we maintain the following:

(1) If figural cues strongly suggest transparency, contradicting indications of the intensity conditions can be overcome (Beck et al., 1984, pp. 411-412, 421). This point is contradicted by the results of our experiments. In particular, the results of Experiment 4 demonstrate that when, apart from figural conditions, motion also favors transparency, transparency is not perceived if intensity conditions are against it.

(2) Figural conditions affect the frequency of transparency (Beck et al., 1984, pp. 411-412). Our experiments confirm this thesis, as demonstrated by the strong difference between the results of Experiment 1, where figural conditions did not suggest transparency, and those of Experiments 3 and 4, where displays did suggest transparency.

(3) Figural conditions are primary (Beck et al., 1984, pp. 412,421 ), that is, they are a necessary cue for perceiving transparency. The results of Experiments 1 and 2 , where this cue was not present, prove that this thesis is not supported by facts.

(4) When two different "versions" of transparency are possible, the version in which there is greater similarity between the two regions concurrently generating the transparent layer occurs more frequently (Beck et al., 1984, pp. 412-414). The assertion is correct, but this fact has been known since 1960 (see Morinaga, Noguchi, \& Osihi, 1962; Petter, 1960).

(5) The violation of "constraints" III and IV does not hinder the perception of transparency [Beck et al., 1984, p. 421 (Experiment 2), pp. 414-415]. Our results confirm this thesis. According to our hypothesis, this means that the visual system admits transparency when there is a different lightness in the $P$ and $Q$ regions.

(6) Although the algebraic deduction evidences the necessary condition that in partial transparency the region where transparency appears must be intermediate in reflectance between the other two regions, Beck et al. (1984, p. 418) hold that there are situations in which the intermediate region is (physically) brighter than the other two regions. This occurs if two projected rectangles of light are partially superimposed. However, it has yet to be verified whether transparency is perceived in this case. 
Table 4

Results of Experiment 4

\begin{tabular}{|c|c|c|c|c|c|c|c|c|}
\hline \multirow{2}{*}{$\begin{array}{c}\text { Displays } \\
\text { Order of } \\
\text { Reflectances } \\
(1) \\
\end{array}$} & \multicolumn{3}{|c|}{ Transparency } & \multirow[b]{2}{*}{$\begin{array}{c}\text { Non- } \\
\text { transparent } \\
(5) \\
\end{array}$} & \multirow{2}{*}{$\begin{array}{c}\text { Double } \\
\text { Response } \\
\text { Description } \\
(6) \\
\end{array}$} & \multirow{2}{*}{$\begin{array}{c}\text { Complete } \\
\text { Transparency } \\
\text { (Beck et al., 1984) } \\
(7)\end{array}$} & \multirow[b]{2}{*}{$\begin{array}{c}\alpha \\
(8) \\
\end{array}$} & \multirow[b]{2}{*}{$\begin{array}{c}t \\
(9)\end{array}$} \\
\hline & $\begin{array}{c}\text { Complete } \\
\text { (2) }\end{array}$ & $\begin{array}{c}\text { Complete } \\
\text { Inverted } \\
(3)\end{array}$ & $\begin{array}{c}\text { Partial } \\
(4)\end{array}$ & & & & & \\
\hline 1 abpq & 5 & - & $4(+2)$ & 1 & $1<\underset{\mathrm{PT}}{\mathrm{CT}} \quad 1<\frac{\mathrm{PT}}{\mathrm{NT}}$ & 15 & .92 & -2.53 \\
\hline 2 apbq & 5 & 1 & $3(+4)$ & - & $4<\frac{\text { CT }}{\text { PT }}$ & 18 & .96 & -2.53 \\
\hline 3 apqb & 10 & - & - & - & - & 18 & .31 & .4 \\
\hline 4 baqp & 1 & 1 & $7(+1)$ & 1 & $1<\underset{\mathrm{PT}}{\mathrm{CIT}}$ & 18 & 1.69 & .79 \\
\hline 5 bqap & 2 & 1 & $5(+2)$ & 2 & $1<{ }_{\mathrm{PT}}^{\mathrm{CT}} 1<{ }_{\mathrm{PT}}^{\mathrm{CIT}}$ & 21 & .96 & -2.53 \\
\hline 6 bqpa & 10 & - & - & - & - & 21 & .31 & .4 \\
\hline 7 qbpa & 7 & 1 & $2(+1)$ & - & $1<\begin{array}{l}\text { CT } \\
\text { PT }\end{array}$ & 21 & 1.04 & -2.53 \\
\hline 8 qpba & 7 & 1 & 3 & - & - & 18 & 1.08 & -2.53 \\
\hline 9 paqb & 1 & - & $9(+1)$ & - & $1<\frac{\mathrm{CT}}{\mathrm{PT}}$ & 18 & 1.04 & -2.53 \\
\hline 10 pqab & 1 & - & 9 & - & - & 17 & 1.08 & -2.53 \\
\hline 11 aqbp & - & - & - & 10 & - & 1 & -.92 & .4 \\
\hline 12 aqpb & 1 & - & - & 9 & - & 2 & -.31 & .41 \\
\hline 13 bpaq & - & - & - & 10 & - & - & -.92 & .4 \\
\hline 14 bpqa & - & - & - & 10 & - & - & -.31 & .41 \\
\hline 15 qapb & - & - & - & 10 & - & - & -1.04 & .41 \\
\hline $16 \mathrm{pbqa}$ & - & - & 4 & 6 & - & 1 & -1.04 & .41 \\
\hline 17 qbap & - & 7 & 2 & 1 & - & - & -3.27 & .4 \\
\hline $18 \mathrm{pabq}$ & - & 9 & 1 & - & - & 1 & -3.27 & .4 \\
\hline 19 qabp & - & - & - & 10 & - & - & -3.27 & .41 \\
\hline 20 pbaq & - & - & - & 10 & - & - & -3.27 & .41 \\
\hline 21 abqp & - & - & 10 & - & - & 3 & -.92 & .4 \\
\hline 22 bapq & - & 1 & $7(+1)$ & 2 & $1<\underset{\mathrm{PT}}{\mathrm{CIT}}$ & 6 & -.92 & .4 \\
\hline 23 qpab & - & - & 10 & - & - & 13 & -1.08 & .4 \\
\hline 24 pqba & - & - & 10 & - & - & 2 & -1.08 & .4 \\
\hline
\end{tabular}

Note $-C I T=$ complete inverted transparency; $C T=$ complete transparency; $P T=$ partial transparency. Apparent motion of the figure upon the ground is added to the favorable conditions in Experiment 3. Notwithstanding the very favorable conditions, there are several situations in which subjects do not see transparency.

(7) According to Beck et al. (1984, p. 418), the equation $\alpha=(p-q) /(a-b)$ is not valid without further restrictions because, for $\alpha=1$, only when $p=a$ and $q=b$ is there maximum transparency, whereas in the other cases, when only the differences $(p-q)$ and $(a-b)$ are equal, only low transparency is perceived. But only in the first case, when $\mathrm{p}=\mathrm{a}$ and $\mathrm{q}=\mathrm{b}$, is there balanced transparency (see Remondino, 1975); in the other cases, where transparency is unbalanced, the formula is inadmissible because it is nondeducible.
(8) By substituting luminances in Equation 3 and comparing them with transparency estimations, Beck et al. obtained a correlation of .62 and, by substituting the means of subjects' lightness matches in Equation 3, obtained a correlation of only .55 between the means of 26 subjects' transparency estimations of eight displays, thus satisfying conditions of balanced transparency and the transparency predicted. Beck et al. concluded that Equation 3 failed to predict the degree of perceived transparency. Our results, on the other hand, suggest cautious optimism. 
Table 5

Results of Experiment 5: $\alpha<0,0<t<1$

\begin{tabular}{|c|c|c|c|c|c|c|c|c|}
\hline \multirow{2}{*}{$\begin{array}{c}\text { Displays } \\
\text { Order of } \\
\text { Reflectances }\end{array}$} & \multicolumn{3}{|c|}{ Transparency } & \multirow[b]{2}{*}{ Nontransparent } & \multirow[b]{2}{*}{$\begin{array}{c}\text { Transparent } \\
\text { Ground }\end{array}$} & \multirow{2}{*}{$\begin{array}{c}\text { Double } \\
\text { Response } \\
\text { Description }\end{array}$} & \multirow[b]{2}{*}{$\alpha$} & \multirow[b]{2}{*}{$\mathbf{t}$} \\
\hline & Complete & $\begin{array}{l}\text { Complete } \\
\text { Inverted }\end{array}$ & Partial & & & & & \\
\hline 1 aqbp & - & - & - & 10 & - & - & -.67 & .33 \\
\hline 2 qabp & - & - & - & 10 & - & - & -1.89 & .45 \\
\hline 3 abqp & - & 6 & $1(+1)$ & $3(+1)$ & - & $1<{ }_{\mathrm{PT}}^{\mathrm{CIT}} 1<\frac{\mathrm{CIT}}{\mathrm{CT}}$ & -.22 & .2 \\
\hline 4 qapb & - & - & 2 & $8(+1)$ & - & $1<\frac{\mathrm{PT}}{\mathrm{NT}}$ & -.59 & .37 \\
\hline 5 qpab & - & - & 1 & $8(+1)$ & 1 & $1<\frac{\mathrm{PT}}{\mathrm{NT}}$ & -.83 & .47 \\
\hline $6 \mathrm{aqpb}$ & - & - & - & 10 & - & - & -.65 & .26 \\
\hline 7 qabp & - & - & - & 10 & - & - & -3.16 & .6 \\
\hline 8 abqp & - & 9 & $1(+1)$ & - & - & $1<\underset{\mathrm{PT}}{\mathrm{CIT}}$ & -.63 & .36 \\
\hline 9 aqbp & - & - & - & 10 & - & - & -1.50 & .58 \\
\hline 10 qapb & - & - & 1 & 9 & - & - & -.83 & .71 \\
\hline
\end{tabular}

Table 6

Results of Experiment 5: $\alpha>1,0<\mathrm{t}<1$

\begin{tabular}{|c|c|c|c|c|c|c|c|c|}
\hline \multirow{2}{*}{$\begin{array}{c}\text { Displays } \\
\text { Order of } \\
\text { Reflectances }\end{array}$} & \multicolumn{3}{|c|}{ Transparency } & \multirow[b]{2}{*}{ Nontransparent } & \multirow{2}{*}{\multicolumn{2}{|c|}{$\begin{array}{c}\text { Double } \\
\text { Response } \\
\text { Description }\end{array}$}} & \multirow[b]{2}{*}{$\alpha$} & \multirow[b]{2}{*}{$\mathrm{t}$} \\
\hline & Complete & $\begin{array}{l}\text { Complete } \\
\text { Inverted }\end{array}$ & Partial & & & & & \\
\hline 11 pabq & - & 2 & 4 & 2 & $2(+1)$ & $1<_{\mathrm{TG}}^{\mathrm{PT}}$ & 1.67 & .34 \\
\hline 12 pabq & - & - & 5 & 3 & $2(+1)$ & $1<\frac{\mathrm{PT}}{\mathrm{TG}}$ & 2.06 & .32 \\
\hline 13 paqb & - & 3 & $6(+2)$ & 1 & - & $2<{ }_{\text {PT }}^{\mathrm{CT}}$ & 1.39 & .15 \\
\hline 14 paqb & 1 & $(+1)$ & 9 & - & $(+2)$ & $1<<_{\mathrm{CIT}}^{\mathrm{CT}} \quad 2<\frac{\mathrm{PT}}{\mathrm{TG}}$ & 2.87 & .06 \\
\hline 15 paqb & - & - & 5 & 3 & $2(+3)$ & $3<\frac{\text { PT }}{\text { TG }}$ & 1.59 & .2 \\
\hline 16 pabq & - & 2 & 7 & - & $1(+2)$ & $2<\frac{\mathrm{PT}}{\mathrm{TG}}$ & 1.76 & .04 \\
\hline 17 paqb & - & 1 & 5 & 2 & $2(+1)$ & $1<\frac{\mathrm{PT}}{\mathrm{TG}}$ & 3.17 & .71 \\
\hline 18 pabq & 1 & - & 8 & 1 & $(+1)$ & $1<_{\mathrm{TG}}^{\mathrm{PT}}$ & 1.71 & .89 \\
\hline 19 apbq & - & 1 & 3 & 4 & $2(+1)$ & $1<\frac{\text { PT }}{\text { TG }}$ & 1.71 & .6 \\
\hline 20 pabq & - & - & 4 & 5 & 1 & - & 2.21 & .9 \\
\hline
\end{tabular}

Note $-P T=$ partial transparency; $T G=$ transparent ground. With $\alpha>I, \alpha \neq \alpha^{\prime}$, results are generally negative, that is, transparency is not perceived.

In Da Pos, Cavedon, and Izzinoso (1985), the relation between estimated and predicted transparency was studied. Experiments were done only in conditions of complete balanced transparency, using episcotisters. Expert subjects were presented with different compositions of displays of transparency, in which the two colors of the ground, the color of the transparent layer, and the degree of physical transparency were changed. The task of the subjects was to give a direct evaluation, using numbers from 0 to 100 , of the degree of transparency in ev- ery situation. These estimates were compared with the corresponding predictions of transparency obtained from the model formally deduced by Metelli (1982), where Munsell values, rather than reflectances, were used.

Eight situations characterized by different combinations of ground (A and B) and color of the transparent layer (T) were considered. For every situation, eight episcotisters of different degrees of physical transparency were used. In Table 9, $\mathrm{r}_{\epsilon \alpha^{*}}$, the correlation between experimental data, $\epsilon$, and theoretical predictions, $\alpha^{*}$, are 
Table 7

Results of Experiment 5: $0<\alpha<1, t>1$

\begin{tabular}{|c|c|c|c|c|c|c|c|c|c|c|c|}
\hline \multirow{2}{*}{$\begin{array}{c}\text { Displays } \\
\text { Order of } \\
\text { Reflectances }\end{array}$} & \multicolumn{3}{|c|}{ Transparency } & \multirow[b]{2}{*}{ Nontransparent } & \multirow[b]{2}{*}{$\begin{array}{c}\text { Transparent } \\
\text { Ground }\end{array}$} & \multirow{2}{*}{\multicolumn{4}{|c|}{$\begin{array}{c}\text { Double } \\
\text { Response } \\
\text { Description }\end{array}$}} & \multirow[b]{2}{*}{$\alpha$} & \multirow[b]{2}{*}{$\mathrm{t}$} \\
\hline & Complete & $\begin{array}{l}\text { Complete } \\
\text { Inverted }\end{array}$ & Partial & & & & & & & & \\
\hline 21 paqb & 1 & 1 & $8(+1)$ & - & $(+1)$ & $1<$ & $\begin{array}{l}\text { CIT } \\
\text { PT }\end{array}$ & $1<$ & $\begin{array}{l}\text { NT } \\
\text { TG }\end{array}$ & .83 & 1.61 \\
\hline 22 pqab & 4 & $(+1)$ & $6(+1)$ & - & - & & - & & & .56 & 1.22 \\
\hline 23 qbpa & 4 & $1(+3)$ & $2(+1)$ & 3 & - & $3<$ & $\begin{array}{l}\text { CT } \\
\text { CIT }\end{array}$ & $1<$ & $\begin{array}{l}\text { CT } \\
\text { PT }\end{array}$ & .97 & 5.91 \\
\hline 24 qbpa & 6 & $2(+2)$ & $2(+3)$ & - & - & $2<$ & $\begin{array}{l}\mathrm{CT} \\
\mathrm{CIT}\end{array}$ & $3<$ & $\begin{array}{l}\text { CT } \\
\text { PT }\end{array}$ & .90 & 1.56 \\
\hline 25 pqab & - & - & 10 & - & - & & - & & & .59 & 1.27 \\
\hline 26 pqab & 2 & - & 7 & 1 & $(+2)$ & $1<$ & $\begin{array}{l}\text { PT } \\
\text { TG }\end{array}$ & $1<$ & $\begin{array}{l}\text { NT } \\
\text { TG }\end{array}$ & .72 & 1.38 \\
\hline 27 pqab & 1 & - & $8(+1)$ & 1 & - & $1<$ & $\begin{array}{l}\text { CT } \\
\text { PT }\end{array}$ & & & .38 & 1.16 \\
\hline 28 paqb & 6 & $(+1)$ & $4(+2)$ & - & - & $1<$ & $\begin{array}{l}\text { CT } \\
\text { CIT }\end{array}$ & $2<$ & $\begin{array}{l}\text { CT } \\
\text { PT }\end{array}$ & .89 & 1.31 \\
\hline 29 paqb & 2 & $(+1)$ & 8 & - & $(+1)$ & $1<$ & $\begin{array}{l}\text { CT } \\
\text { CIT }\end{array}$ & $1<$ & $\begin{array}{l}\text { PT } \\
\text { GT }\end{array}$ & .83 & 1.50 \\
\hline 30 paqb & 4 & $(+1)$ & $6(+1)$ & - & - & $1<$ & $\begin{array}{l}\text { CT } \\
\text { CIT }\end{array}$ & $1<$ & $\begin{array}{l}\text { CT } \\
\text { PT }\end{array}$ & .89 & 1.31 \\
\hline
\end{tabular}

Note $-C I T=$ complete inverted transparency; $C T=$ complete transparency; $N T=$ non-transparent $; P T$ $=$ partial transparency; $T G=$ transparent ground. With $t<0\left(t \neq t^{\prime}\right)$ while $\alpha=\alpha^{\prime}$, unbalanced transparency is not uncommon.

Table 8

Results of Experiment 5: $0<\alpha<1, t<0$

\begin{tabular}{|c|c|c|c|c|c|c|c|c|c|}
\hline \multirow{2}{*}{$\begin{array}{c}\text { Displays } \\
\text { Order of } \\
\text { Reflectances } \\
\end{array}$} & \multicolumn{3}{|c|}{ Transparency } & \multirow[b]{2}{*}{ Nontransparent } & \multirow[b]{2}{*}{$\begin{array}{c}\text { Transparent } \\
\text { Ground }\end{array}$} & \multirow{2}{*}{\multicolumn{2}{|c|}{$\begin{array}{c}\text { Double } \\
\text { Response } \\
\text { Description } \\
\end{array}$}} & \multirow[b]{2}{*}{$\alpha$} & \multirow[b]{2}{*}{$\mathrm{t}$} \\
\hline & Complete & $\begin{array}{l}\text { Complete } \\
\text { Inverted }\end{array}$ & Partial & & & & & & \\
\hline 31 apbq & 3 & $(+3)$ & 7 & - & - & $3<$ & $\begin{array}{l}\text { CT } \\
\text { CIT }\end{array}$ & .81 & -.64 \\
\hline 32 apbq & 1 & - & $9(+1)$ & - & - & $1<$ & $\begin{array}{l}\text { CT } \\
\text { PT }\end{array}$ & .88 & -.05 \\
\hline 33 abpq & 1 & $(+1)$ & 8 & 1 & - & $1<$ & $\begin{array}{l}\text { CT } \\
\text { CIT }\end{array}$ & .36 & -.04 \\
\hline 34 apbq & 3 & $(+2)$ & 6 & 1 & - & $2<$ & $\begin{array}{l}\text { CT } \\
\text { CIT }\end{array}$ & .69 & -.05 \\
\hline 35 abpq & 2 & $(+2)$ & 7 & 1 & - & $2<$ & $\begin{array}{l}\text { CT } \\
\text { CIT }\end{array}$ & .52 & -.48 \\
\hline 36 abpq & 1 & $1(+1)$ & $5(+1)$ & 3 & - & $1<$ & $\underset{\mathrm{CIT}}{\mathrm{CT}} \quad 1<{ }_{\mathrm{PT}}^{\mathrm{CIT}}$ & .25 & -.04 \\
\hline 37 abpq & 1 & $(+1)$ & 9 & - & - & $1<$ & $\begin{array}{l}\text { CT } \\
\text { CIT }\end{array}$ & .68 & -.9 \\
\hline $38 \mathrm{abpq}$ & 4 & $(+4)$ & 6 & - & - & $4<$ & $\begin{array}{l}\text { CT } \\
\text { CIT }\end{array}$ & .96 & -.64 \\
\hline 39 abpq & 6 & $(+5)$ & $4(+1)$ & - & - & $5<$ & $\begin{array}{l}\text { CT } \\
\text { CIT }\end{array} \quad 1<{ }_{\mathrm{PT}}^{\mathrm{CT}}$ & .64 & -.38 \\
\hline $40 \mathrm{abpq}$ & 1 & $(+1)$ & 9 & - & $(+1)$ & $1<$ & $\begin{array}{l}\text { CT } \\
\text { CIT }\end{array} \quad 1<\frac{\text { TG }}{\text { PT }}$ & .49 & -.41 \\
\hline
\end{tabular}

Note $-C I T=$ complete inverted transparency; $C T=$ complete transparency; $P T=$ partial transparency; $T G=$ transparent ground. With $t>1\left(t \neq t^{\prime}\right)$ while $\alpha=\alpha^{\prime}$, unbalanced transparency is not uncommon. Beck et al.'s hypothesis is confirmed.

presented. Values of $\mathbf{n}$ (intercept) and $m$ (slope) of the regression straight line are also given.

As can be seen, the results appear to provide a confirmation of the theoretical model proposed by Metelli (1982).

\section{CONCLUSIONS}

Beck et al. (1984) concluded that the perception of transparency is a function of stimulus information indicating that an overlying surface is not opaque but transpar- 
Table 9

Results of Da Pos, Cavedon, and Izzinoso Experiments

\begin{tabular}{|c|c|c|c|c|}
\hline & $\begin{array}{c}1 \\
a=\text { dark gray } \\
b=\text { black } \\
t=\text { white } \\
\end{array}$ & $\begin{array}{c}\mathrm{a}=\text { medium gray } \\
\mathrm{b}=\text { dark gray } \\
\mathrm{t}=\text { white }\end{array}$ & $\begin{array}{c}3 \\
a=\text { medium gray } \\
b=\text { dark gray } \\
t=\text { black }\end{array}$ & $\begin{array}{c}4 \\
a=\text { white } \\
b=\text { light gray } \\
t=\text { black }\end{array}$ \\
\hline $\begin{array}{l}\mathbf{r}_{e}, \alpha^{*} \\
\mathrm{n} \\
\mathrm{m}\end{array}$ & $\begin{array}{r}.92 \\
-.07 \\
1.22\end{array}$ & $\begin{array}{r}.99 \\
-.06 \\
1.11\end{array}$ & $\begin{array}{r}.95 \\
-.18 \\
1.09\end{array}$ & $\begin{array}{c}.96 \\
-.2 \\
1.1\end{array}$ \\
\hline & $\begin{array}{c}5 \\
a=\text { white } \\
b=\text { black } \\
t=\text { dark gray }\end{array}$ & $\begin{array}{c}6 \\
a=\text { white } \\
b=\text { light gray } \\
t=\text { dark gray }\end{array}$ & $\begin{array}{c}7 \\
a=\text { medium gray } \\
b=\text { dark gray } \\
t=\text { light gray }\end{array}$ & $\begin{array}{c}8 \\
a=\text { white } \\
b=\text { medium gray } \\
t=\text { light gray }\end{array}$ \\
\hline $\begin{array}{l}\mathbf{r}_{\varepsilon, \alpha}{ }^{*} \\
\mathrm{n} \\
\mathrm{m}\end{array}$ & $\begin{array}{l}.94 \\
.14 \\
.93\end{array}$ & $\begin{array}{c}.97 \\
0 \\
.98\end{array}$ & $\begin{array}{l}.95 \\
.02 \\
.99\end{array}$ & $\begin{array}{l}.96 \\
.06 \\
.93\end{array}$ \\
\hline
\end{tabular}

Note-Results of Da Pos, Cavedon, and Izzinoso (in press) experiments. $a, b=$ colors of the ground; $t=$ color of the episcotister; $r_{\varepsilon, \alpha}{ }^{*}=$ correlation between estimated $(\epsilon)$ and calculated $\left(\alpha^{*}\right)$ degree of transparency; $n=$ intercept, $m=$ slope of the regression line. The degree of transparency was calculated with $\alpha^{*}$ formula, using Munsell Values. Since the correlation is close to 1 and the values of the intercept and of the slope are negligible, it seems to be possible to predict the estimated transparency from the formula: $\alpha^{*}=\left(p^{*}-q^{*}\right) /\left(a^{*}-b^{*}\right)$, where $p^{*} q^{*} a^{*} b^{*}$ are Munsell Values instead of reflectances.

ent. We cannot accept this assertion, because in our experiments transparency was perceived in stimulus situations devoid of any such information.

Notwithstanding the results of Beck et al.'s (1984) Experiment 3 and $\mathrm{Da}$ Pos et al.'s (1985) results with estimation of transparency, the scission notion would still seem to offer an adequate description of the process of transparency, even if scission took place at a higher level.

The most interesting result of Beck et al.'s study seems to be that transparency takes place in the form of nonbalanced transparency with regard to color (Beck et al., 1984 , pp. 408,421 )-that is, when two regions of the transparent layer differ with regard to color-and not when two regions of the transparent layer ought to show a difference in the degree of transparency. This is the import of the assertion that, while the "constraints" regarding the degree of transparency, $\alpha$, hold, "constraints" regarding color, $t$, can be violated without transparency's being hindered. We see no reason for asserting that "constraints" III and IV are based on the physical variable of luminance or reflectance (Beck et al., 1984, p. 421), as though "constraints" I and II were not. All four "constraints" can be expressed in terms of physical or psychological variables, according to the data used in the respective formulas.

There is no doubt that transparency depends on figural as well as chromatic or intensity conditions. But, for reasons indicated above, we cannot agree with the assertion of Beck et al. that figural conditions are primary, namely that they are essential for the perception of transparency. In fact, we proved that transparency is also perceived in cases in which no figural conditions act in favor of transparency. But obviously transparency is more likely to be perceived when it is favored by figural conditions. However, figural conditions never become coercive. In- deed, in our experiments with displays like the one illustrated in Figure 6, where transparency is favored by motion, there are displays which, notwithstanding the interfigural apparent motion of the two partially superimposed circles, do not give rise to the perception of transparency. The paradoxical case observed by Metzger (1955) does not occur when, in place of color differences, there are differences of intensity.

To assert that the phenomenon consists of encoding a color in the color of an opaque surface and in that of a transparent surface (Beck et al., 1984) means, in other words, that chromatic scission takes place. If, on the other hand, coding is intended as an intellectual activity, then the old hypothesis of unconscious judgments is revived, a hypothesis that we consider unacceptable.

Beck et al. (1984, p. 422) speak of necessary sensory support to this intellectual activity. But, although it is quite clear that we see red and yellow in orange, and red and blue in purple, in their experiments with different shades of gray we do not see white and black in gray. As for other supports, such as highlights, border contrast, color at the boundaries, or flecks of the nontransparent color, they are only accidental factors. The theory must take into account only necessary conditions.

\section{REFERENCES}

Beck, J., Prazdny, K., \& Ivry, R. (1984). The perception of transparency with achromatic colors. Perception \& Psychophysics, 35, 407-422.

Da Pos, O., Cavedon, A., \& Izzinoso, F. (1985). La stima soggettiva dei parametri della trasparenza. Atti e Memorie dell'Accademia Patavina di Scienze. Lettere ed Arti. 97.

Heider, G. M. (1933). New studies in transparency, form and color. Psychologische Forschung, 17, 13-56.

KoffKA, K. (1935). Principles of Gestalt psychology. New York: Harcourt Brace. 
Meteld, F. (1970). An algebraic development of the theory of perceptual transparency. Ergonomics, 13, 59-66.

METELLI, F. (1974a). Achromatic color conditions in the perception of transparency. In R. B. Macleod \& H. L. Pick (Eds.), Perception (pp. 95-116). Ithaca, NY: Cornell University Press.

Meteldi, F. (1974b). The perception of transparency. Scientific American, 230(4), 90-98

Metelli, F. (1975). On the visual perception of transparency. In G. B. Flores D'Arcais (Ed.), Studies in perception (pp. 445-487). Milan: Martello.

METELLI, F. (1982). Stimulation and perception of transparency (Report No. 73). Padua, Italy: University of Padua, Institute of Psychology.

Metelli, F. (1985). Su alcune condizioni spazio-figurali della trasparenza. In W. Gerbino (Ed.), Conoscenza e struttura (pp. 303331). Bologna: Il Mulino.

Metzger, W. (1955). Über Durchsichtigkeits-Erscheinungen (Vorläufige Mitteilung). Rivista di Psicologia, 49, 187-189.

Morinaga, S., Noguchi, K., \& OSIHI, A. (1962). Dominance of main direction in the apparent transparency. Japanese Psychological Research, 4, 113-128.

Petter, G. (1960). Osservazioni sulla trasparenza fenomenica. Rivista di Psicologia, 54, 183-186.

Remondino, C. (1975). Achromatic color conditions in the perception of transparency: The development of an analytical model. In G. B. Flores D'Arcais. (Ed.), Studies in perception (pp. 111-138). Milan: Martello.

\section{NOTES}

1. Only achromatic colors are considered in this paper (white-grayblack) which can be described by only one number, the reflectance, which is the proportion of light reflected by a gray surface of a given shade.

2. Capital letters indicate regions, and small letters indicate the respective reflectances.

3. The above symbols (ABPQ) used in the preceding papers by Metelli (1970, 1974a, 1974b, 1975, 1982) were changed by Beck et al. (1984) into ABDC. But we stick to our symbols for clarity. $P$ and $Q$ are the regions where transparency takes or could take place and $A$ and $B$ are the background colors. $P$ is the region where $A$ is seen through transparency and $Q$ is the region through which $B$ is seen.

4. Because $\alpha$ is the lacking sector of the episcotister, and $t$ is the color of the episcotister.

5. If $\alpha>1$, then $(1-\alpha)<0$. In this case, as in the case of $\alpha<0$, it appears from Equations 1 and 2 that either the transparent region or the region seen through transparency receives a negative quantity of color, which is devoid of meaning. Since $t$ is a reflectance, $t>1$ or $t<0$ means that a region would reflect or absorb more light than the quantity falling on it, which is equally absurd.

6. The above explanations are, in our opinion, sufficient to justify the use of expert subjects in this research. But there are other reasons speaking for the use of expert subjects in experimentation in perception, where phenomenological description is required. "Naive" subjects are by no means naive, because, since they are asked to give a phenomenological description, they readily make up their own interpretations or opinions about the phenomenon that is being studied, and interpret instead of describing.

Phenomenological description is a difficult task, and only expert subjects are able to resist the temptation to say what they think, instead of saying what they see or in general perceive.

7. However, it has to be stressed that we never intended to minimize the importance of figural conditions.

Here we used neutral figural conditions, that is conditions allowing but not suggesting stratification; but there are several necessary figural conditions (Metelli, 1975, 1985). Our intention was only to show that figural cues are not necessary in order to perceive transparency.

In this case, it might have been better to use a group of naive subjects as well; but probably the difference with the above results would not be crucial, because naive subjects have to be pretrained for the task (see Beck et al., 1984, p. 409). However, O. Da Pos, when attending the 1985 Mundial Color Congress in Monte Carlo, learned of studies in which subjects with the task of comparing colors in displays like Figure 3 spontaneously described impressions of stratification and transparency when particular combinations of colors were present.

8. The task of Beck et al.'s subjects was to declare "nontransparent" all cases of transparency (partial, inverse) except those localized in the QP regions (see Figure 5).

(Manuscript received March 18, 1985;

revision accepted for publication September 13, 1985.) 